This is a peer-reviewed, accepted author manuscript of the following article: Khan, T., Hussain, S., Ikram, A., Mahmood, S., Riaz, H., Jamil, A., ... Godman, B. (2020). Prevalence and treatment of neurological and psychiatric disorders among tertiary hospitals in Pakistan; findings and implications. Hospital Practice. https://doi.org/10.1080/21548331.2020.1762366

\title{
Prevalence and treatment of neurological and psychiatric disorders among tertiary hospitals in Pakistan; findings and implications
}

Tanveer Ahmed Khan 1 , Shahzad Hussain 1 , Aamer Ikram¹, Sidra Mahmood², Humayun Riaz ${ }^{3}$, Ayesha Jamil $^{4}$, Amina Amin ${ }^{4}$, Yaseen Ghulam Haider ${ }^{5}$, Marva Sandhu1 ${ }^{1}$, Atifa Mushtaq ${ }^{1}$, Corrado Barbui ${ }^{6}$, Chris F Johnson 7 , Brian Godman $8,9,10,11$

${ }^{1}$ National Institute of Health, Islamabad, Pakistan. Emails: tanveerahmedkhan754@gmail.com; shahzadpharmacist1962@gmail.com; maahin1@yahoo.com; marvasandhu90@hotmail.com; atifa_mushtaq@yahoo.com

2Department of Pharmacy, Quaid-e-Äzam University, Islamabad, Pakistan. Email:

sidraphd19@gmail.com

3Rashid Latif College of Pharmacy, Lahore-Pakistan. Email: humayunriaz@hotmail.com

${ }^{4}$ Faculty of Pharmacy, Hajvery University, Lahore, Pakistan. Email: ador5bles@gmail.com; aamna.amin11@gmail.com

${ }^{5}$ Department of Pharmacy, University of Lahore, Lahore, Pakistan. Email:

yaseenhaider51@gmail.com

6WHO Collaborating Centre for Research and Training in Mental Health and Service Evaluation,

Department of Neuroscience, Biomedicine and Movement Sciences, Section of Psychiatry, University of

Verona, Italy. Email: corrado.barbui@univr.it.

7Pharmacy Services, National Health Service Greater Glasgow and Clyde (NHS GGC), Glasgow, UK.

Email: c.johnson2@nhs.net

${ }^{8}$ Department of Laboratory Medicine, Division of Clinical Pharmacology, Karolinska Institute,

Karolinska University Hospital Huddinge, Stockholm, Sweden. Email: Brian.Godman@ki.se

${ }^{9}$ Department of Pharmacoepidemiolgy, Strathclyde Institute of Pharmacy and Biomedical Sciences,

Strathclyde University, Glasgow, UK. Email: Brian.Godman@strath.ac.uk

${ }^{10} \mathrm{Health}$ Economics Centre, Liverpool University, Liverpool, UK. Email:

Brian.Godman@liverpool.ac.uk

${ }^{11}$ Division of Public Health Pharmacy and Management, School of Pharmacy, Faculty of Health

Sciences, Sefako Makgatho Health Sciences University, Pretoria, Guanteng Province, South Africa

*Author for correspondence: Division of Clinical Pharmacology, Karolinska Institute, Karolinska University Hospital Huddinge, SE-141 86, Stockholm, Sweden. Email: Brian.Godman@ki.se. Telephone + 468 58581068. Fax + 46859581070 and Strathclyde Institute of Pharmacy and Biomedical Sciences, University of Strathclyde, Glasgow G4 ORE, United Kingdom. Email: Brian.godman@strath.ac.uk. Telephone: 0141548 3825. Fax: 01415522562 and

Key words: Psychiatric disorders, neurological disorders, schizophrenia, depression, drug abuse, smoking, Pakistan

(Accepted for publication in Hospital Practice)

\footnotetext{
Abstract

Introduction: Mental health and neurological disorders are prevalent in Pakistan. However, there are considerable concerns with their management due to issues of access, availability of trained personnel and stigma alongside paucity of such data. Consequently, there is a need to document current treatment approaches starting with tertiary hospitals in Pakistan where patients with more severe mental and neurological disorders are typically treated. Subsequently, use the findings to help direct future policies and initiatives. Methods: Multi-centred, cross-sectional, prospective study principally evaluating current medicine usage among patients attending tertiary hospitals in Pakistan with psychiatric and neurological disorders. In addition, possible factors contributing to the prevalence of these disorders in this population to help with future care. All 23 tertiary care hospitals in the ten major Districts in Pakistan were included, which cover 75\% of the population. Results: 57664 patients were evaluated of which $35.3 \%$ were females. Both females and males had multiple brain disorders and multiple co-morbidities. Schizophrenia was the most prevalent disorder overall among both females $(25.2 \%)$ and males (30.4\%). A median of six medicines were prescribed per patient, with antipsychotics and antidepressants the most prescribed medicines. Clozapine was the most prescribed medicine in males (12.25\%) and females (11.83\%) including for psychiatric disorders, with
} 
sodium valproate the most prescribed medicine in epilepsy in males $(42.44 \%$ of all anti-epileptic medicines) as well as females (46.38\%). There was a greater prevalence of both disorders among the lower classes. A greater prevalence of schizophrenia was seen in patients abusing alcohol and smokers. The divorce rate was higher among the studied patients and the prevalence of depression was higher among the widowed population. Conclusions: There were concerns with the quality of prescribing including the extent of polypharmacy as well as possible overuse of clozapine especially in patients with epilepsy, both of which need addressing.

\section{INTRODUCTION}

\subsection{Mental health issues across countries LMICs and in Pakistan}

Mental health disorders currently account for between 10 to $13 \%$ of the global burden of diseases, although others have documented higher rates (1-7). The global burden of these disorders has risen in recent years, especially among lower- and middle-income countries (LMICs), as a result of demographic, environmental and socio-political changes (8-10). However, there are challenges as there is currently limited government spending on mental disorders across LMICs as well as typically only a limited number of professionals available in LMICs to treat patients with mental health conditions $(3,4,10-12)$. Typically in LMICs, mental health services are lacking, and large segments of the population do not have ready access to mental health service professionals and/ or receive inadequate care $(7,13-16)$.

In Pakistan, mental problems currently affect between $10-16 \%$ of the population or greater $(17,18)$, most of whom are women. These high rates in Pakistan are exacerbated by increasing unemployment rates, insecurity, political fluctuations, disruption of social norms and a high percentage of the population living below the poverty level (19-21). However, the provision of mental health services is a challenge in Pakistan especially regarding important issues such as access to appropriate care $(18,21)$. There are currently no specific community based residential facilities or community based out-patient treatment facilities for patients with psychiatric disorders in Pakistan. , This is not helped by the fact that the majority of the Pakistani population are unwilling to accept people having mental health problems, which results in active discrimination towards those with psychiatric disorders in the country (21).

Typically care for patients with psychiatric disorders is provided in hospitals in Pakistan, which include both tertiary care hospitals as well as secondary care hospitals in the large cities, with patients living in both rural and urban areas typically visiting these facilities for their care. Overall, there are 1280 tertiary care hospitals in Pakistan. However, access to care and medicines as well as misplaced beliefs may lead patients to seek help from local religious healers and practitioners of traditional medicines rather than healthcare professionals, which can result in very limited relief (21). Women in Pakistan face an even greater risk of psychiatric disorders with challenges accessing services as well as being subject to domestic violence (21). Encouragingly though, more patients with psychiatric disorders are now accessing professionals in Pakistan as a result of the growing awareness of these disorders and the ability of healthcare professionals to treat these (21). Having said this, there are continuing concerns with the training of physicians in Pakistan regarding the treatment of patients with psychiatric disorders, which is similar to many other LMICs $(5,10)$,

\subsection{Neurological diseases in LMICs including Pakistan}

Neurological diseases are also a concern, and does include psychiatric disorder co-morbidities (22). This is certainly the case among patients referred to tertiary hospitals in Pakistan for their treatment. In their 2006 report, the WHO estimated that by $2030,80 \%$ of all strokes will occur in LMICs (23). As economies improve in LMICs, with associated changes in lifestyle, diet and the environment, the prevalence of diseases more often associated with Western countries will increase. This has been the case with for instance high rates of cardiovascular diseases now found among LMICs including subSaharan African countries with changes in diet and lifestyles (24-27).

In Pakistan, there was a $13.5 \%$ increase in the prevalence of neurological disorders in all age groups as well as disability-adjusted life-years (DALYs) from 1990 to 2015 , and a $18.5 \%$ decrease in age standardised rates in the same period (28). Epilepsy is seen as the second most burdensome neurological condition worldwide (29). Current prevalence rates in Pakistan are 10 per 1000 persons, with people living in urban areas nearly twice as likely to have epilepsy compared with those living in rural areas (30). Females are also more likely to have epilepsy (10.9 per 1000 persons) than males 
(9.2 per 1000 persons) (30). The rate of strokes is also rising in Pakistan similar to other LMICs with growing rates of cardiovascular disease $(31,32)$, with an estimated annual incidence of 250 per 100,000 of the population, which translates into approximately 350,000 new cases of stroke every year in Pakistan (33). Currently, one in four people in Pakistan has either hypertension, type-2 diabetes or cardiovascular disease $(34,35)$, increasing the burden of stroke in the future unless adequately addressed.

We would like to build on these studies to help with the future care of patients with psychiatric and neurological diseases in Pakistan given the current paucity of publications documenting this. There is also a need to document current medicines prescribed to act as a basis for developing pertinent treatment guidelines for patients with these conditions in Pakistan given current concerns with the training of physicians in Pakistan to treat patients with psychiatric disorders. In addition, identifying possible triggers to the development of psychiatric and neurological disorders to help with future prevention strategies. Pertinent quality improvement programmes can also be proposed starting with the most severe patients based on a situational analysis of current treatments. This is similar to the philosophy behind point prevalence studies for antimicrobials in Pakistan and across countries (3639).

We are aware that studies have been conducted in other countries documenting treatment patterns in patients with neurological and psychiatric disorders, and are just starting in Pakistan including cross national surveys $(21,40-42)$. However, we believe it is important to conduct such studies in Pakistan as Pakistan is currently the sixth most populous country of the world with an estimated population of 207.77 million in 2017 (43). There are also concerns with the stigma associated with psychiatric disorders in Pakistan, access to care especially in patients with multiple co-morbidities and appropriate prescribing given the paucity of national standard treatment guidelines (STGs) in Pakistan and limited physician training $(5,10,44)$. Additional concerns include issues with inappropriate polypharmacy in patients with multiple co-morbidities enhanced by the lack of STGs and physician training. Addressing identified concerns should help improve the future management of patients with both psychiatric and neurological disorders in Pakistan especially given the paucity of such data in Pakistan. The findings may well be of interest to other LMICs struggling to optimally treat patients with psychiatric and neurological disorders.

\subsection{Aims of the study}

The aims of the study are to document current prevalence proportions, co-morbidities, treatments including issues of polypharmacy, and possible factors in the management of patients with neurological and psychiatric disorders attending tertiary hospitals in Pakistan. By starting with the more severe cases, we believe our findings will help inform physicians and policy makers regarding key issues including current drug utilisation patterns. As a result, help improve the future care of such patients in the Islamic Republic of Pakistan. The lessons learnt in the more severe cases can be used generally to help improve the care of such patients throughout Pakistan with most patients with psychiatric disorders currently treated in secondary and tertiary care facilities in Pakistan.

\section{MATERIALS AND METHODS}

\subsection{Overview of the study}

A multi-centred, cross-sectional, prospective drug utilisation study was designed to principally document current medicines prescribed and prevalence proportions for patients with various neurological and psychiatric disorders attending tertiary hospitals across the Islamic Republic of Pakistan. This includes patients with joint co-morbidities. In addition, possible factors influencing the development of these disorders.

We focused on ten major districts among three of the four provinces in Pakistan to give a good representation of Pakistan. We did not add Baluchistan due to law and order concerns in this province. The ten major Districts included Karachi, Hyderabad and Mirpur Khas (Sindh), Peshawar and Abbottabad (Khyber Pakhtunkhawa), Lahore, Faisalabad, Multan, Sargodha and Gujranwala (Punjab), which represent $75 \%$ of the Pakistani population, and included all 23 tertiary care hospitals providing such care out of a total of 1280 tertiary care hospitals throughout Pakistan. 
Data was collected from tertiary care hospitals, since, as mentioned, this is where patients with neurological and mental health disorders are typically treated in Pakistan when not seeking care from local religious healers or practitioners of traditional medicines.

Data were collected between April 2016 to March 2018. We included all tertiary care hospitals providing care for such patients in this initial comprehensive study as we did not wish to undertake a selection of possible cases as we felt this might bias any findings. Consequently, no statistical analysis was undertaken to determine possible patient numbers for further analysis.

\subsection{Inclusion and exclusion criteria}

All outpatients and inpatients presenting to the tertiary hospitals during the study period with psychiatric and/or neurological disorders were included in the study. There was no gender discrimination and no random selection of patients. However, patients were broken down where pertinent into males and females given issues of domestic violence and also females currently live longer than males in Pakistan (67.4 years versus 65.7 years for males (45)).

However, patients were excluded if they were pregnant, were unconscious or in a coma, had malignancy or HIV or were disabled. This was in order to focus on the primary conditions and any associated co-morbidities, any ongoing pharmacologic treatment and any potential underlying factors. We were aware based on our experiences that the psychiatric condition among pregnant patients in Pakistan may well change following the delivery of their child. Consequently, we excluded pregnant mothers from our study. The patients who died during the study period were also removed from the study. Past medical history, alcohol and drug abuse, smoking habits, and social status were also considered with alcohol and drug misuse, as well as smoking, related to neurological and psychiatric conditions $(46,47)$.

The various neurological and psychiatric disorders were evaluated based on ICD-10 (48) and included: Attention Deficit Hyperactivity Disorder (ADHD), Central Auditory Processing Disorder (CAPD), Cerebral Atrophy, Cerebral Palsy, Cluster Headache, Dementia, Drug dependence disorders such as alcohol dependence disorder, Epilepsy, Insomnia, Mentally retardation, Migraine, Parkinson's disease, Parkinsonism and Psychiatric disorders including Attention Deficit Hyperactivity Disorder, Alzheimer's Disease, Bipolar Affective Disorder (BAD), Body Dysmorphic Disorder, Depression, Generalized Anxiety Disorder, Hypomania, Mania, Mood Disorder, Obsessive-Compulsive Disorder (OCD), Paranoia, Phobia, Postpartum Depression, Psychosis, Post-Traumatic Stress Disorder (PTSD) and Schizophrenia. Excluded conditions included sexual dysfunctions, personality disorders, dissociative disorders, somatoform disorders, neuralgia, and demyelinating disorder. The diagnosis was taken from the patient's notes and in discussions with patients with no additional follow-up of physicians. We have included both schizophrenia and psychosis. This is because schizophrenia is a mental illness that causes psychosis; however, schizophrenia also has other symptoms and it is not the only cause of psychosis. Other mental illnesses that cause psychosis including depression, bipolar disorders, dementia and borderline personality disorder. Psychosis may also occur during times of extreme stress, lack of sleep, or trauma. Psychosis may also be caused by a brain injury, neurological problems, or other health problems. Consequently, while psychosis can be a part of schizophrenia, it can be caused by many other factors as well.

\subsection{Questionnaire design and collection of survey data}

A patient history proforma was designed based on Neurology Questionnaire of Physician's Clinic of lowa, USA (49) and piloted prior to the study. The survey team were subsequently trained in the use of the standardised questionnaire before initiating the study. After obtaining informed consent, the questionnaire was administered face-to-face in settings that provided maximum privacy by trained personnel, with the questions asked in English, Urdu or a regional language depending upon the patient's capabilities. If the patient answered in Urdu or a regional language, this was converted to English acknowledging that some concepts may not be the same across languages (50). However, concerns were minimised by using trained researchers fluent in the pertinent languages.

The standardised questionnaire included demographic data (age, gender, and address), dietary habits, tobacco and alcohol consumption $(46,47)$, medical history, socioeconomic status based on income, family history, symptoms of neurological conditions including chronic headaches and, seizures, as well as current medications for psychiatric and neurological disorders. Medicines were classified according to their chemical (INN) name (51). No attempt was made to classify medicines as 
an originator, branded generic or generic, as this was not the main aim of this paper. We further assessed medicine use in the four most prevalent conditions to add further insight into current treatment modalities among this patient population, which was a descriptive assessment.

We are aware that many factors that combine together to affect the health of individuals and communities. The determinants of health include social, economic, and physical environments as well as people's individual characteristics and behaviours (52). We are also aware that marital relationship is also an important component of family and social support, and failure to reach or maintain a marriage can go against social norms and expectations in a number of countries including Pakistan, which may influence the extent of especially psychological conditions (53-55). Consequently, we considered the income status, family history including patients' stress conditions, and marital status of patients in our study. We also included family history because conditions including ADHD,

Alzheimer's disease, epilepsy, Parkinson's Disease and OCD may run in families (56). We also looked further at smoking habits $(57,58)$, alcoholic intake $(46,47)$, and drug misusers $(47,59)$, in view of their potential impact on neurological and psychiatric disorders.

We defined low-income as patients earning up to US\$200 per month; middle-income between US $\$ 200$ and US $\$ 750$ per month, and greater than US $\$ 750$ per month as high-income in line with salaries of personnel in the government and private sectors. Patients' ages were also broken down into 10 age bands in line with other studies, i.e. $0-9$ years, $10-19$ years, $20-29$ years, $30-39$ years, $40-49$ years, $50-59$ years, $60-69$ years, $70-79$ years, $80-89$ and above $(60,61)$.

\subsection{Statistical Analysis}

Anonymised responses were subsequently entered onto an Excel spreadsheet for analysis. Descriptive statistics and crude prevalence proportions were calculated for the different neurological and psychiatric conditions for patients attending the tertiary hospitals in the various districts of Pakistan during the study period.

Crude prevalence proportions were calculated by dividing the total number of cases during the course of the study by the total number of people attending the tertiary hospitals in the ten major districts among three of the four provinces in Pakistan for these various disorders and adjusting for one year.

Univariate linear regression was used to evaluate the changes. When dealing with age groups, interquartile range (IQR) was identified and applied. All the analyses were undertaken in SPSS version 22 (IBM Corporation USA). No other statistical tests were undertaken as this paper was principally a situational analysis rather than testing any pre-defined hypotheses.

\subsection{Ethical considerations}

Ethical approval for the study was obtained from the Institutional Ethical Committee of Rashid Latif College of Pharmacy, Lahore. Written informed consent was obtained before enrolling participants into the study.

\section{RESULTS}

\subsection{Patient demographics}

Overall 57,664 patients met the inclusion criteria, of which $35.32 \%$ were females with a median age (IQR) of 40 (5 to 91 ) years and $64.68 \%$ were males with a median age of 47.5 (5-91 inter quartile range). Most patients were also lower economic status (Table 1).

Insert Table 1

\subsection{Distribution of neurological and psychiatric disorders according to age and gender among the study participants}

Figure 1 documents the prevalence of the various neurological and psychiatric disorders among the studied patients.

Insert Figure 1

Both females and males had multiple brain disorders as shown in Table 2. Schizophrenia was the most prevalent disorder among both males and females. Males had the lowest prevalence of ADHD 
and Parkinson's Disease among those with these formal diagnoses whilst females had the least prevalence of PTSD and post partum depression (Table 2).

\section{Insert Table 2}

Patients with epilepsy were typically younger with a median age of 27 (IQR 5 to 70) years versus those with other disorders (Appendix A1). Among patients with neurological disorders, the median age for schizophrenia, psychosis and bipolar affective disorders (BAD) was 31, 32 and 35 years respectively.

Schizophrenia, depression, and epilepsy were among the highest prevalence diagnoses in the study group with Parkinson's disease, postpartum depression, PTSD and ADHD the least common disorders (Table 3). It was found that schizophrenia was most prevalent disorder in males $(30.4 \%)$ as well as females $(25.2 \%)$ followed by depression $10.8 \%$ and $20.0 \%$ respectively (Table 3 ). Overall, there were low prevalence rates for CAPD, cerebral palsy, hypomania, postpartum depression, PTSD and ADHD (Table 3).

\section{Insert Table 3}

57,644 patients were prescribed 207,488 medicines (total number of medicines), with a median of six medicines per patient, with antipsychotics and antidepressants the most prescribed medicines in both males and females (Table 4). Of these, $77.29 \%(n=160368)$ were psychotropics for schizophrenia and depression with a median of two medicines per patient (Table 5). Clozapine was the most prescribed medicine in males $(12.25 \%)$ and females $(11.83 \%)$, with trifluoperazine $(0.02,0.02 \%)$, ziprasidone $(0.02,0.02 \%)$, oxazepam $(0.02,0.01 \%)$, and duloxetine $(0.02,0.0 \%)$ the least prescribed in females and males with clofazimine $(0.01 \%)$ also the least prescribed in males $(p=0.000)$.

\section{Insert Table 4}

The most frequently prescribed medicine among females and males in all age groups with schizophrenia was clozapine (22.17 and $22.27 \%$ of all medicines prescribed for schizophrenia) (Table $5)$, with promethazine the least prescribed antipsychotic for schizophrenia in males $(9.08 \%)$ and olanzapine the least prescribed in females. Clozapine was also the most prescribed medicine for patients with depression potentially reflecting multiple psychiatric disorders in the studied population. However, sodium valproate was the most prescribed medicine in epilepsy in males $(42.44 \%$ of all anti-epileptic medicines) as well as females $(46.38 \%)$, while carbamazepine was least prescribed medicine in males (19.59\%) and mirtazapine the least in females (17.47\%). Details of patients' comorbidities are included in the Appendix.

\section{Insert Table 5}

The most frequently diagnosed disorder in smokers was schizophrenia in males $(30.63 \%)$ and females $(23.53 \%)$. Schizophrenia was also prevalent in patients abusing alcohol (36.36\%). Male drug misusers $(31.32 \%)$ also had schizophrenia, which was mostly followed by depression (13.65\%) (Table $6)$.

Insert Table 6

\subsection{Potential causes of neurological and psychiatric Disorders}

We further studied family history to ascertain possible factors which could affect the prevalence of psychiatric and neurological disorders in our patient population (Table 7).

\section{Insert Table 7}

We found that patients suffering from neurological and psychiatric problems had more fluctuations in their marital affairs (Table 1). Of the 57,664 subject participants in the present study, 22,864 were single. The marriage rate among the subjects of our study was $58.46 \%$ compared to $63.04 \%$ for the National marital rate according to Pakistan Bureau of Statistics (43). The divorce rate among the studied population was $1.10 \%$, which is more than double the $0.34 \%$ rate among the general population (43). It was also observed that the prevalence of depression was high in both male 
$(5.55 \%)$ and female (50\%) widowed populations in our study, whilst there was a high rate of schizophrenia in single and married women $(26.99 \%, 25.44 \%$ respectively) and men $(30.37 \%$, $30.25 \%$ respectively).

\section{DISCUSSION}

We believe this is the most comprehensive study undertaken to date among patients with neurological and psychiatric conditions attending tertiary hospitals in Pakistan to guide future management and policy decisions Both males and females had multiple brain disorders and co-morbidities (Table 2, Appendix B). Overall, schizophrenia, depression, and epilepsy were among the most prevalent diseases within the study group (Table 3), with Parkinson's disease, postpartum depression, PTSD and ADHD the least common (Table 3). This was reflected in the high use of antipsychotics and antidepressants among this population, accounting for a total of $62.9 \%$ to $64.1 \%$ of all medicines prescribed in females and males respectively (Table 4).

Among those with neurological disorders, the median age for schizophrenia, psychosis and Bipolar affective disorders (BAD) was 31, 32 and 35 years respectively. Other studies have also suggested age and gender differences in the onset of schizophrenia $(62,63)$. This may be due to differences in diagnostic rates, life styles and living conditions between the patients in the various studies.

There was an appreciable number of medicines prescribed for the patients in our study (Table 4). The high rate of polypharmacy is a concern with a median of six medicines per patient. This may reflect the extensive co-morbidities in the studied patients similar to other studies assessing rates of polypharmacy among patients in Asia including Pakistan with appreciable psychiatric disorders (40, 41). However, this will need closer monitoring as polypharmacy is known to increase the rate of adverse drug reactions with associated increases in hospitalisations, morbidity and mortality as well as negatively impact on adherence rates to the medicines prescribed (64-68). There are a number of initiatives that can subsequently be undertaken to reduce rates of inappropriate prescribing, and we will be looking at these in the future $(66,69-71)$.

Clozapine was the most frequently prescribed medicine overall (Table 4) as well as in patients with schizophrenia and depression (Table 5), and the second most prescribed medicine in patients with epilepsy (Table 5). This is a concern in patients with depression and epilepsy and will be looked at further; however, this may reflect bias from self-reported illness which may actually represent complex psychiatric co-morbidities or schizoaffective and bipolar disorders rather than solely depression or principally epilepsy $(72,73)$. This was the same for both sexes, with the high use of clozapine similar to other studies of patients with schizophrenia (74), especially those with more severe disease (21, 75-77), with trifluoperazine, ziprasidone, oxazepam, and duloxetine, the least prescribed in females and males with clofazimine the least prescribed in males (Table 4).

There were also concerns that $12 \%$ of patients prescribed a psychotropic medicine were also coprescribed a benzodiazepine, which is not good clinical practice. However, this is similar to other studies involving patients with severe psychiatric problems in Pakistan (41). It is unclear though if the benzodiazepines were prescribed as acute rescue medicines or for chronic long-term use. Even so, benzodiazepines are known to worsen cognitive impairment $(78)$, depressive symptoms $(79,80)$, and reduce the effectiveness of some psychological therapies (81) as well as being associated with increased mortality for people with schizophrenia (82). Consequently, their prescribing needs to be carefully considered as part of future management strategies in patients with appreciable comorbidities, and will be researched further. This can be part of the development of STGs in these patients alongside regular medication reviews and improved physician education regarding mental health disorders. This though requires key physicians from pertinent tertiary hospitals to come together to develop and refine treatment guidelines for their patients in Pakistan with psychiatric and neurological disorders. A starting point could be pertinent international guidelines; however, adapted for the local situation. This important activity could be under the direction of the College of Physicians in Pakistan. Locally produced guidelines with trusted physicians appear to have good adherence in practice as seen for instance in Sweden with its guidance and list of prescribed medicines $(83,84)$. Such activities, including addressing high rates of polypharmacy, could also be part of any national action plan for patients with mental and neurological disorders in Pakistan, building on WHO and national initiatives across countries $(7,10,85-87)$. 
There was also limited prescribing of promethazine similar to other studies $(21,88)$. Harrison and others have concluded that early recognition of treatment resistance schizophrenia and the use of clozapine appears to be associated with reduced hospitalisation $(89,90)$, supporting its use among patients with schizophrenia in these tertiary centres in Pakistan (Tables 4 and 5). Consequently, it is difficult to fully comment on the appropriateness of clozapine prescribing, which can again be part of any future quality initiatives.

However, our findings are different to Mahmood et al where olanzapine and risperidone were the most prescribed antipsychotics with more limited prescribing of clozapine. This is because their study was conducted in more general (secondary) hospitals compared to just tertiary hospitals (21). Our study population with high rates of co-morbidities (Appendix B) is reflected in the high use of clozapine and sodium valproate in patients with depression (Table 6) reflecting a greater prevalence of bipolar disorders especially bipolar depression. Sodium valproate is prescribed for maintenance treatments in patients with bipolar disorders in view of its effectiveness and tolerability compared with other treatments $(91,92)$. Sodium valproate was also the most prescribed medicine in male patients with epilepsy as well as in females, whilst carbamazepine was the least prescribed in males and mirtazapine the least in females (Table 5). The appreciable use of clozapine and antidepressants in patients with epilepsy reflects, as mentioned, extensive co-morbidities (Appendix B) similar to other studies (93). Overall, the medicine utilisation patterns seen in our study is different from conventional treatments in ambulatory care due to the large number of co-morbidities (Appendix B) and the availability of medicines in the hospital formulary.

The most frequently diagnosed disorder in smokers was schizophrenia in both males and females (Table 6). This is perhaps not surprising with several studies showing that patients with schizophrenia have an extremely high prevalence of smoking, almost $90 \%$, compared to only $33 \%$ in the general population and $45-70 \%$ in patients with other psychiatric diagnoses (94-96). Rates of smoking though are now much lower in the general population in developed countries following several campaigns $(97,98)$. Government campaigns may also start to reduce smoking rates in Pakistan similar to other countries, enhanced by the banning of smoking in public places $(99,100)$. Schizophrenia was also prevalent in alcoholics (Table 6) (101-103) and male drug misusers $(104,105)$, followed by depression (Table 6) which have a known association $(104,105)$.

Family history appeared to have an influence on the prevalence of psychiatric and neurological disorders in our patient population (Table 7). Multiple studies have also revealed that socioeconomic status is a major cause in the progression of neurological and psychiatric disorders (106-109). The prevalence of depression was high in both male and female widowed populations in our study, whilst there was a high rate of schizophrenia in single and married women and men. Several studies have also shown an association between marital status and psychiatric disorders $(110,111)$.

We are aware there are a number of limitations with our study. These include the fact that we concentrated only on tertiary hospitals in Pakistan without including secondary care hospitals with more generalised populations for the reasons given. We also only assessed prescribing practices at one point in time rather than longitudinally, and we did not assess the rationale behind prescribing practices. We also relied on the responses from patients for a number of social, economic and other factors, although we are aware that it can be very difficult in Pakistan to interview patients with psychiatric disorder as they can be non-responsive especially those from rural areas. However, despite these limitations, we believe our findings are robust given their extensive nature providing a background to the development of suitable initiatives to improve the future care of these patients in Pakistan.

In conclusion, there is a high prevalence of neurological and psychiatric disorders in LMICs such as Pakistan. We have identified a number of factors and issues that we believe increase their prevalence. There are also extensive co-morbidities leading to multiple medicines being prescribed which can be inappropriate as well as concerns with the prescribing of clozapine and benzodiazepines in some patients. These concerns will be researched further given the known association between polypharmacy and medicine adherence rates as well as potential adverse effects, and we will be reporting on this in due course.

\section{Key Points}


- There are considerable co-morbidities among patients with mental health and neurological disorders being treated at tertiary hospital in Pakistan

- These co-morbidities lead to polypharmacy among patients with a median of six medicines per patient, with high use of clozapine among the patient groups.

- There are concerns with some of the drug combinations prescribed which needs addressing to reduce morbidity and mortality alongside reviewing the need for an appreciable number of medicines in some patients

- There is also need to standardise management approaches for patients with mental health and neurological disorders among the tertiary hospitals in Pakistan given a lack of standardised treatment guidance to date. Once undertaken, prescribing can be assessed against agreed guidance to improve future care

\section{DECLARATION OF FUNDING}

The study was self-funded.

\section{CONFLICT OF INTEREST}

Authors declare they have no conflicts of interest.

\section{Data availability}

Data is available on request.

\section{ORCID Numbers}

Tanveer Ahmed Khan: http://orcid.org/0000-0001-5970-3972

Shahzad Hussain: http://orcid.org/0000-0002-8849-6455

Aamer Ikram: http://orcid.org/0000-0002-6440-750X

Yaseen Ghulam Haider: http://orcid.org/0000-0001-5601-4063

Atifa Mushtaq: http://orcid.org/0000-0003-2178-3350

Brian Godman: http://orcid.org/0000-0001-6539-6972

Chris F Johnson: http://ORCID ID: 0000-0002-6006-6605

Corrado Barbui: https://orcid.org/0000-0003-1073-9282

\section{References}

1. Steel Z, Marnane C, Iranpour C, Chey T, Jackson JW, Patel V, et al. The global prevalence of common mental disorders: a systematic review and meta-analysis 1980-2013. International journal of epidemiology. 2014;43(2):476-93.

2. Vigo D, Thornicroft G, Atun R. Estimating the true global burden of mental illness. The lancet Psychiatry. 2016;3(2):171-8.

3. Patel V. Mental health in low- and middle-income countries. British medical bulletin. 2007;8182:81-96

4. WHO-AIMS. Mental health systems in selected low- and middle-income countries: a WHO-

AIMS cross-national analysis. 2009. Available at URL:

http://www.who.int/mental_health/evidence/who_aims_report_final.pdf

5. Naqvi HA, Sabzwari S, Hussain S, Islam M, Zaman $\bar{M}$. General practitioners' awareness and management of common psychiatric disorders: a community-based survey from Karachi, Pakistan.

East Mediterr Health J. 2012;18(5):446-53.

6. Kessler RC, Aguilar-Gaxiola S, Alonso J, Chatterji S, Lee S, Ormel J, et al. The global burden of mental disorders: An update from the WHO World Mental Health $(\mathrm{WMH})$ Surveys. Epidemiologia e psichiatria sociale. 2009;18(1):23-33.

7. World Health Organization. Improving access to and appropriate use of medicines for mental disorders. 2017. Available at URL:

file://C:/Users/mail/Desktop/My\%20documents/Ongoing\%20papers/Scotland\%20SSRIs/WHO\%20Me ntal\%20Health\%202018.pdf.

8. Patel V, Saxena S, Lund C, Thornicroft G, Baingana F, Bolton P, et al. The Lancet Commission on global mental health and sustainable development. Lancet. 2018;392(10157):155398.

9. WHO. Management of physical health conditions in adults with severe mental disorders. Available at URL: https://apps.who.int/iris/bitstream/handle/10665/275718/9789241550383eng.pdf?ua=1.

10. Godman B, Grobler C, Van-De-Lisle M, Wale J, Barbosa WB, Massele A, et al.

Pharmacotherapeutic interventions for bipolar disorder type II: addressing multiple symptoms and 
approaches with a particular emphasis on strategies in lower and middle-income countries. Expert opinion on pharmacotherapy. 2019;20(18):2237-55.

11. Hendler R, Kidia K, Machando D, Crooks M, Mangezi W, Abas M, et al. "We Are Not Really Marketing Mental Health": Mental Health Advocacy in Zimbabwe. PloS one. 2016;11(9):e0161860. 12. WHO Mental Health Gap Action Programme. mhGAP Intervention Guide. 2016. Available at URL: file:///C:/Users/mail/Downloads/9789241549790-eng.pdf.

13. Bruckner TA, Scheffler RM, Shen G, Yoon J, Chisholm D, Morris J, et al. The mental health workforce gap in low- and middle-income countries: a needs-based approach. Bull World Health Organ. 2011;89(3):184-94.

14. Demyttenaere K, Bruffaerts R, Posada-Villa J, Gasquet I, Kovess V, Lepine JP, et al. Prevalence, severity, and unmet need for treatment of mental disorders in the World Health Organization World Mental Health Surveys. Jama. 2004;291(21):2581-90.

15. Ahmad I, Khalily MT, Hallahan B, Shah I. Factors associated with psychotic relapse in patients with schizophrenia in a Pakistani cohort. International journal of mental health nursing. 2017;26(4):384-90.

16. Ezenduka C, Ubochi V, Ogbonna BO. The Utilization Pattern and Costs Analysis of Psychotropic Drugs at a Neuropsychiatric Hospital in Nigeria. British Journal of Pharmaceutical Research. 2014;4(3):325-37.

17. Gadit A. State of mental health in Pakistan. JOURNAL-PAKISTAN MEDICAL ASSOCIATION. 2001;51(7):238-.

18. Altaf A, Khan M, Shah SR, Fatima K, Tunio SA, Hussain M, et al. Sociodemographic Pattern of Depression in Urban Settlement of Karachi, Pakistan. Journal of Clinical and Diagnostic Research. 2015;9(6):VC09-VC13.

19. Khalily M. Mental health problems in Pakistani society as a consequence of violence and trauma: a case for better integration of care. International Journal of Integrated Care. 2011;11:1-7.

20. Gadit AA. Mental health in Pakistan: where do we stand? JPMA. 2006;56(5):198-9.

21. Mahmood S, Hussain S, Ur Rehman T, Barbui C, Kurdi AB, Godman B. Trends in the prescribing of antipsychotic medicines in Pakistan: implications for the future. Current medical research and opinion. 2019;35(1):51-61.

22. 2019 ICD 10 - Other symptoms and signs involving the nervous system. Available at URL: https://www.icd10data.com/ICD10CM/Codes/R00-R99/R25-R29/R29-/R29.818.

23. Mathers CD, Loncar D. Projections of global mortality and burden of disease from 2002 to 2030. PLoS Med. 2006;3(11):e442.

24. Nashilongo MM, Singu B, Kalemeera F, Mubita M, Naikaku E, Baker A, et al. Assessing Adherence to Antihypertensive Therapy in Primary Health Care in Namibia: Findings and Implications. Cardiovascular drugs and therapy. 2017;31(5-6):565-78.

25. Meyer JC, Schellack N, Stokes J, Lancaster R, Zeeman H, Defty D, et al. Ongoing Initiatives to Improve the Quality and Efficiency of Medicine Use within the Public Healthcare System in South Africa; A Preliminary Study. Frontiers in pharmacology. 2017;8:751.

26. Mbui JM, Oluka MN, Guantai EM, Sinei KA, Achieng L, Baker A, et al. Prescription patterns and adequacy of blood pressure control among adult hypertensive patients in Kenya; findings and implications. Expert review of clinical pharmacology. 2017;10(11):1263-71.

27. Godman B, Basu D, Pillay Y, Mwita JC, Rwegerera GM, Anand Paramadhas BD, et al. Review of Ongoing Activities and Challenges to Improve the Care of Patients With Type 2 Diabetes Across Africa and the Implications for the Future. Frontiers in pharmacology. 2020;11(108).

28. Kassebaum NJ, Arora M, Barber RM, Bhutta ZA, Brown J, Carter A, et al. Global, regional, and national disability-adjusted life-years (DALYs) for 315 diseases and injuries and healthy life expectancy (HALE), 1990-2015: a systematic analysis for the Global Burden of Disease Study 2015. The Lancet. 2016;388(10053):1603-58.

29. Fiest KM, Sauro KM, Wiebe S, Patten SB, Kwon C-S, Dykeman J, et al. Prevalence and incidence of epilepsy: a systematic review and meta-analysis of international studies. Neurology. 2017;88(3):296-303.

30. Shakirullah S, Ali N, khan A, Nabi M. The Prevalence, Incidence and Etiology of Epilepsy. International Journal of Clinical and Experimental Neurology. 2014;2(2):29-39.

31. Riaz H, Godman B, Bashir S, Hussain S, Mahmood S, Waseem D, et al. EVALUATION OF DRUG USE INDICATORS FOR NON-COMMUNICABLE DISEASES IN PAKISTAN. Acta poloniae pharmaceutica. 2016;73(3):787-94.

32. Khealani BA, Hameed B, Mapari UU. Stroke in Pakistan. JPMA. 2008;58(7):400-3.

33. Khalid W, Rozi S, Ali TS, Azam I, Mullen MT, Illyas S, et al. Quality of life after stroke in Pakistan. BMC neurology. 2016;16(1):250. 
34. Iqbal Q, Bashir S, Iqbal J, Iftikhar S, Godman B. Assessment of medication adherence among type 2 diabetic patients in Quetta city, Pakistan. Postgraduate medicine. 2017;129(6):637-43.

35. Jafar TH, Haaland BA, Rahman A, Razzak JA, Bilger M, Naghavi M, et al. Non-communicable diseases and injuries in Pakistan: strategic priorities. The Lancet. 2013;381(9885):2281-90.

36. Saleem Z, Hassali MA, Versporten A, Godman B, Hashmi FK, Goossens H, et al. A multicenter point prevalence survey of antibiotic use in Punjab, Pakistan: findings and implications. Expert review of anti-infective therapy. 2019;17(4):285-93.

37. Anand Paramadhas BD, Tiroyakgosi C, Mpinda-Joseph P, Morokotso M, Matome M, Sinkala $\mathrm{F}$, et al. Point prevalence study of antimicrobial use among hospitals across Botswana; findings and implications. Expert review of anti-infective therapy. 2019;17(7):535-46.

38. Versporten A, Zarb P, Caniaux I, Gros MF, Drapier N, Miller M, et al. Antimicrobial consumption and resistance in adult hospital inpatients in 53 countries: results of an internet-based global point prevalence survey. The Lancet Global health. 2018;6(6):e619-e29.

39. Finlayson H, Versporten A, Whitelaw A, Goossens H, Taljaard J. . The Global Point Prevalence Survey of Antimicrobial Consumption and Resistance (Global-PPS): Results of antimicrobial prescribing in a South African Tertiary Hospital. Available at URL: http://www.globalpps.com/wp-content/uploads/ECCMID-2016_South-Africa.pdf. 2016.

40. Dong M, Zeng LN, Zhang Q, Yang SY, Chen LY, Sim K, et al. Antipsychotic Polypharmacy in Older Adult Asian Patients With Schizophrenia: Research on Asian Psychotropic Prescription Pattern. Journal of geriatric psychiatry and neurology. 2019;32(6):304-11.

41. Dong M, Zeng LN, Zhang Q, Yang SY, Chen LY, Najoan E, et al. Prescription of antipsychotic and concomitant medications for adult Asian schizophrenia patients: Findings of the 2016 Research on Asian Psychotropic Prescription Patterns (REAP) survey. Asian journal of psychiatry. 2019;45:7480.

42. Malik M, Ghani MU, Mazhar W, Munir N. Changing trends in anti-psychotic prescription pattern in Pakistan. Pak J Med Sci. 2019;35(3):653-7.

43. Pakistan Bureau of Statistics. 2017. Available at URL: http://www.pbs.gov.pk/.

44. Riaz H, Godman B, Hussain S, Malik F, Mahmood S, Shami A, Bashir S. Prescribing of bisphosphonates and antibiotics in Pakistan: challenges and opportunities for the future. JPHSR 2015;6:111-21.

45. World Life Expectancy. Available at URL: www. worldlife expectancy.com.

46. Leposavić L, Dimitrijević D, Đorđević S, Leposavić I, Nikolić Balkoski G. Comorbidity of harmful use of alcohol in population of schizophrenic patients. Psychiatria Danubina. 2015;27(1):0-89.

47. Regier DA, Farmer ME, Rae DS, Locke BZ, Keith SJ, Judd LL, et al. Comorbidity of mental disorders with alcohol and other drug abuse: results from the Epidemiologic Catchment Area (ECA) study. Jama. 1990;264(19):2511-8.

48. CDC. National Centre for Health Statistics. International Classification of Diseases, Tenth Revision (ICD-10). Available at URL: https://www.cdc.gov/nchs/icd/icd10cm.htm.

49. Physicians' Clinic of lowa, P.C. NEUROLOGY QUESTIONNAIRE. Available at URL:

https://www.pcofiowa.com/files/6514/0043/1586/Neuro_Questionnaire_0513.pdf.

50. Pilgrim D, Bentall R. The medicalisation of misery: a critical realist analysis of the concept of depression. J Mental Health. 1999;8(3):261-74.

51. WHO. WHO Collaborating Centre for Drug Statistics Methodology. Guidelines for ATC Classification and DDD Assignment. 2017. Available at URL:

https://www.whocc.no/filearchive/publications/2017_guidelines_web.pdf [

52. Marmot M. Social determinants of health inequalities. The lancet. 2005;365(9464):1099-104.

53. Bachrach LL. Marital status and mental disorder: An analytical review: US Dept. of Health, Education, and Welfare, Public Health Service, Alcohol, Drug Abuse, and Mental Health Administration, National Institute of Mental Health; 1975.

54. Williams DR, Takeuchi DT, Adair RK. Marital status and psychiatric disorders among blacks and whites. Journal of Health and Social Behavior. 1992:140-57.

55. Bloom BL, Asher SJ, White SW. Marital disruption as a stressor: A review and analysis.

Psychological bulletin. 1978;85(4):867.

56. Riddle MA, Scahill L, King R, Hardin MT, Towbin KE, Ort SI, et al. Obsessive compulsive disorder in children and adolescents: phenomenology and family history. Journal of the American Academy of Child \& Adolescent Psychiatry. 1990;29(5):766-72.

57. Pomerleau OF, Downey KK, Stelson FW, Pomerleau CS. Cigarette smoking in adult patients diagnosed with attention deficit hyperactivity disorder. Journal of substance abuse. 1995;7(3):373-8.

58. McCabe RE, Chudzik SM, Antony MM, Young L, Swinson RP, Zolvensky MJ. Smoking

behaviors across anxiety disorders. Journal of anxiety disorders. 2004;18(1):7-18. 
59. Loranger AW, Sartorius N, Andreoli A, Berger P, Buchheim P, Channabasavanna S, et al. The international personality disorder examination: The World Health Organization/Alcohol, Drug Abuse, and Mental Health Administration international pilot study of personality disorders. Archives of General Psychiatry. 1994;51(3):215-24.

60. Wig NN, Varma VK, Mattoo SK, Behere PB, Phookan HR, Misra AK, et al. An incidence study of schizophrenia in India. Indian J Psychiatry. 1993;35(1):11-7.

61. Hussain G, Shahzad A, Anwar H, Mahmood Baig S, Shabbir A, De Aaguilar J-IG.

Neurological disorder burden in Faisalabad, Punjab-Pakistan: data from the major tertiary carecenters of the city. Pakistan Journal of Neurological Sciences (PJNS). 2017;12(3):3-10.

62. Castle DJ, Wessely S, Murray RM. Sex and schizophrenia: effects of diagnostic stringency, and associations with premorbid variables. The British Journal of Psychiatry. 1993;162(5):658-64.

63. Ochoa S, Usall J, Villalta-Gil V, Vilaplana M, Márquez M, Valdelomar M, et al. Influence of age at onset on social functioning in outpatients with schizophrenia. The European journal of psychiatry. 2006;20(3):157-63.

64. Maher RL, Hanlon J, Hajjar ER. Clinical consequences of polypharmacy in elderly. Expert opinion on drug safety. 2014;13(1):57-65.

65. Rankin A, Cadogan CA, Patterson SM, Kerse N, Cardwell CR, Bradley MC, et al. Interventions to improve the appropriate use of polypharmacy for older people. The Cochrane database of systematic reviews. 2018;9:Cd008165.

66. Thomas RE, Thomas BC. A Systematic Review of Studies of the STOPP/START 2015 and American Geriatric Society Beers 2015 Criteria in Patients $>/=65$ Years. Current aging science. 2019;12(2):121-54.

67. Pirmohamed M, James S, Meakin S, Green C, Scott AK, Walley TJ, et al. Adverse drug reactions as cause of admission to hospital: prospective analysis of 18820 patients. BMJ. 2004;329(7456):15-9.

68. Sarwar MR, Dar AR, Mahar SY, Riaz T, Danish U, Iftikhar S. Assessment of prescribing potentially inappropriate medications listed in Beers criteria and its association with the unplanned hospitalization: a cross-sectional study in Lahore, Pakistan. Clinical interventions in aging. 2018;13:1485-95.

69. Butool I, Nazir S, Afridi M, Shah SM. Evaluation and assessment of prescribing patterns in elderly patients using two explicit criteria based screening tools: (The PRISCUS list and STOPP/START criteria). Pak J Med Sci. 2018;34(6):1357-62.

70. Urfer M, Elzi L, Dell-Kuster S, Bassetti S. Intervention to Improve Appropriate Prescribing and Reduce Polypharmacy in Elderly Patients Admitted to an Internal Medicine Unit. PloS one. 2016;11(11):e0166359.

71. Sarwar MR, Iftikhar S, Sarfraz M. Influence of Education Level of Older Patients on Polypharmacy, Potentially Inappropriate Medications Listed in Beer's Criteria, and Unplanned Hospitalization: A Cross-Sectional Study in Lahore, Pakistan. Medicina. 2018;54(4).

72. Li XB, Tang YL, Wang CY, de Leon J. Clozapine for treatment-resistant bipolar disorder: a systematic review. Bipolar disorders. 2015;17(3):235-47.

73. Ciapparelli A, Dell'Osso L, Bandettini di Poggio A, Carmassi C, Cecconi D, Fenzi M, et al. Clozapine in treatment-resistant patients with schizophrenia, schizoaffective disorder, or psychotic bipolar disorder: a naturalistic 48-month follow-up study. The Journal of clinical psychiatry. 2003;64(4):451-8.

74. Wheeler AJ. Treatment pathway and patterns of clozapine prescribing for schizophrenia in New Zealand. Annals of Pharmacotherapy. 2008;42(6):852-60.

75. Leucht S, Cipriani A, Spineli L, Mavridis D, Orey D, Richter F, et al. Comparative efficacy and tolerability of 15 antipsychotic drugs in schizophrenia: a multiple-treatments meta-analysis. Lancet. 2013;382(9896):951-62.

76. Smith RC, Leucht S, Davis JM. Maximizing response to first-line antipsychotics in schizophrenia: a review focused on finding from meta-analysis. Psychopharmacology. 2018.

77. Siskind D, McCartney L, Goldschlager R, Kisely S. Clozapine v. first- and second-generation antipsychotics in treatment-refractory schizophrenia: systematic review and meta-analysis. The British journal of psychiatry. 2016;209(5):385-92.

78. Dell'osso B, Lader M. Do benzodiazepines still deserve a major role in the treatment of psychiatric disorders? A critical reappraisal. European psychiatry : the journal of the Association of European Psychiatrists. 2013;28(1):7-20.

79. Ashton $\mathrm{H}$. Protracted withdrawal syndromes from benzodiazepines. Journal of substance abuse treatment. 1991;8(1-2):19-28. 
80. Kripke DF. Greater incidence of depression with hypnotic use than with placebo. BMC psychiatry. 2007;7:42.

81. Otto MW, Bruce SE, Deckersbach T. Benzodiazepine use, cognitive impairment, and cognitive-behavioral therapy for anxiety disorders: issues in the treatment of a patient in need. The Journal of clinical psychiatry. 2005;66 Suppl 2:34-8.

82. Tiihonen J, Mittendorfer-Rutz E, Torniainen M, Alexanderson K, Tanskanen A. Mortality and Cumulative Exposure to Antipsychotics, Antidepressants, and Benzodiazepines in Patients With Schizophrenia: An Observational Follow-Up Study. The American journal of psychiatry. 2016;173(6):600-6.

83. Gustafsson LL, Wettermark B, Godman B, Andersen-Karlsson E, Bergman U, Hasselstrom J, et al. The 'wise list'- a comprehensive concept to select, communicate and achieve adherence to recommendations of essential drugs in ambulatory care in Stockholm. Basic \& clinical pharmacology \& toxicology. 2011;108(4):224-33.

84. Eriksen J, Gustafsson LL, Ateva K, Bastholm-Rahmner P, Ovesjo ML, Jirlow M, et al. High adherence to the 'Wise List' treatment recommendations in Stockholm: a 15-year retrospective review of a multifaceted approach promoting rational use of medicines. BMJ open. 2017;7(4):e014345.

85. Public Health England. Mental health action plan: PHE response. 2014. Available at URL: https://www.gov.uk/government/news/mental-health-action-plan-phe-response.

86. Australian Government Department of Health. The Fifth National Mental Health and Suicide Prevention Plan. 2017. Available at URL:

http://www.health.gov.au/internet/main/publishing.nsf/Content/mental-fifth-national-mental-healthplan.

87. WHO. Comprehensive mental health action plan 2013-2020. 2013. Available at URL:

https://www.who.int/mental_health/action_plan_2013/en/.

88. Magliano L, Fiorillo A, Guarneri M, Marasco C, De Rosa C, Malangone C, et al. Prescription of psychotropic drugs to patients with schizophrenia: an Italian national survey. European journal of clinical pharmacology. 2004;60(7):513-22.

89. Harrison J, Janlöv M, Wheeler AJ. Patterns of clozapine prescribing in a mental health service in New Zealand. Pharmacy world \& science. 2010;32(4):503-11.

90. Land R, Siskind D, McArdle P, Kisely S, Winckel K, Hollingworth SA. The impact of clozapine on hospital use: a systematic review and meta-analysis. Acta psychiatrica Scandinavica.

2017;135(4):296-309.

91. Cipriani A, Reid K, Young AH, Macritchie K, Geddes J. Valproic acid, valproate and divalproex in the maintenance treatment of bipolar disorder. The Cochrane database of systematic reviews. 2013;2013(10):Cd003196.

92. Geddes JR, Goodwin GM, Rendell J, Azorin JM, Cipriani A, Ostacher MJ, et al. Lithium plus valproate combination therapy versus monotherapy for relapse prevention in bipolar I disorder (BALANCE): a randomised open-label trial. Lancet. 2010;375(9712):385-95.

93. Kühn K-U, Quednow BB, Thiel M, Falkai P, Maier W, Elger CE. Antidepressive treatment in patients with temporal lobe epilepsy and major depression: a prospective study with three different antidepressants. Epilepsy \& Behavior. 2003;4(6):674-9.

94. Lohr JB, Flynn K. Smoking and schizophrenia. Schizophrenia research. 1992;8(2):93-102.

95. Šagud M, Mihaljević-Peleš A, Mück-Šeler D, Pivac N, Vuksan-Ćusa B, Brataljenović T, et al. Smoking and schizophrenia. Psychiatria Danubina. 2009;21(3):371-5.

96. Goff DC, Henderson DC, Amico E. Cigarette smoking in schizophrenia: relationship to psychopathology and medication side effects. Am J Psychiatry. 1992;149(9):1189-94.

97. Anonymous. Smoking rates in UK falls to second-lowest in Europe. The Guardian. 2017.

98. Griesbach D, Amos A, Currie C. Adolescent smoking and family structure in Europe. Social science \& medicine. 2003;56(1):41-52.

99. Ministry of National Health Services, Regulations and Coordination. Government of Pakistan.

Tobacco Control Cell. 2018. Available at URL: http://www.tcc.gov.pk/

100. Pakistan. Tobacco control laws. 2005. Available at URL:

https://www.tobaccocontrollaws.org/legislation/country/pakistan/summary.

101. Bowie CR, Serper MR, Riggio S, Harvey PD. Neurocognition, symptomatology, and functional skills in older alcohol-abusing schizophrenia patients. Schizophrenia Bulletin. 2005;31(1):175-82.

102. D'Souza DC, Gil RB, Madonick S, Perry EB, Forselius-Bielen K, Braley G, et al. Enhanced sensitivity to the euphoric effects of alcohol in schizophrenia. Neuropsychopharmacology. 2006;31(12):2767.

103. Drake RE, Osher FC, Wallach MA. Alcohol use and abuse in schizophrenia: a prospective community study. Journal of nervous and mental Disease. 1989. 
104. Mueser KT, Yarnold P, Bellack A. Diagnostic and demographic correlates of substance abuse in schizophrenia and major affective disorder. Acta Psychiatrica Scandinavica. 1992;85(1):48-55.

105. Mueser KT, Yarnold PR, Levinson DF, Singh H, Bellack AS, Kee K, et al. Prevalence of substance abuse in schizophrenia: demographic and clinical correlates. Schizophrenia Bulletin. 1990;16(1):31-56.

106. Evans GW, Kantrowitz E. Socioeconomic status and health: the potential role of environmental risk exposure. Annual review of public health. 2002;23(1):303-31.

107. Hesdorffer DC, Tian H, Anand K, Hauser WA, Ludvigsson P, Olafsson E, et al. Socioeconomic status is a risk factor for epilepsy in Icelandic adults but not in children. Epilepsia. 2005;46(8):1297-303.

108. Sattler C, Toro P, Schönknecht P, Schröder J. Cognitive activity, education and socioeconomic status as preventive factors for mild cognitive impairment and Alzheimer's disease. Psychiatry research. 2012;196(1):90-5.

109. Alanis-Guevara I, Pena E, Corona T, Lopez-Ayala T, Lopez-Meza E, Lopez-Gomez M. Sleep disturbances, socioeconomic status, and seizure control as main predictors of quality of life in epilepsy. Epilepsy \& Behavior. 2005;7(3):481-5.

110. Lensi P, Cassano GB, Correddu G, Ravagli S, Kunovac J, Akiskal HS. ObsessiveCompulsive Disorder: Familial-Developmental History, Symptomatology, Comorbidity and Course with Special Reference to Gender-Related Differences. The British Journal of Psychiatry. 1996;169(1):101-7.

111. Helmer C, Damon D, Letenneur L, Fabrigoule C, Barberger-Gateau P, Lafont S, et al. Marital status and risk of Alzheimer's disease A French population-based cohort study. Neurology. 1999;53(9):1953-. 
Tables

Table 1 - Patient demographics

\begin{tabular}{|c|c|c|}
\hline \multicolumn{3}{|c|}{ Population Demographics } \\
\hline Age (Years) & Females & Males \\
\hline & n (\%) & n (\%) \\
\hline $0-9$ & $160(0.8)$ & $96(0.3)$ \\
\hline $10-19$ & $2080(10.3)$ & $5328(14.3)$ \\
\hline $20-29$ & $5776(28.5)$ & $13712(36.7)$ \\
\hline $30-39$ & $5712(28.2)$ & $9888(26.5)$ \\
\hline $40-49$ & $2688(13.3)$ & $5392(14.4)$ \\
\hline $50-59$ & $1984(9.8)$ & $1584(4.2)$ \\
\hline $60-69$ & $1152(5.7)$ & $976(2.6)$ \\
\hline $70-79$ & $624(3.1)$ & $272(0.7)$ \\
\hline $80-89$ & $64(0.3)$ & $80(0.2)$ \\
\hline $90-99$ & $16(0.1)$ & $16(0.0)$ \\
\hline Economic status & n (12752) & n (21456) \\
\hline Lower Income (Class) & $12496 *(97.99)$ & $14976(69.80)$ \\
\hline Middle Income (Class) & $240(1.88)$ & $5712(26.62)$ \\
\hline Upper Income (Class) & $16(0.12)$ & $768(3.58)$ \\
\hline \multicolumn{3}{|l|}{ *11056 are house wives. } \\
\hline \multicolumn{3}{|l|}{ Marital Status } \\
\hline Single & 5216 & 17648 \\
\hline Married & 14304 & 19408 \\
\hline Separated & 96 & 2 \\
\hline Divorced & 448 & 192 \\
\hline Widowed & 288 & 16 \\
\hline
\end{tabular}

NB: 11056 patients were housewives without income with a number of patients also dependent on others for their income including parents 
Table 2 - Distribution of neurological and psychiatric disorders among study participants in order of prevalence

\begin{tabular}{|c|c|c|}
\hline Disorder & $\begin{array}{c}\text { Female } \\
(n=19095)\end{array}$ & $\begin{array}{c}\text { Male } \\
(n=34965)\end{array}$ \\
\hline Schizophrenia & 5136 & 11328 \\
\hline Depression & 4064 & 4032 \\
\hline Epilepsy & 2656 & 3920 \\
\hline GAD & 1328 & 3536 \\
\hline OCD & 1328 & 3024 \\
\hline Mood Disorder & 1168 & 2784 \\
\hline BAD & 1088 & 1408 \\
\hline Psychosis & 976 & 1248 \\
\hline Mania & 848 & 2064 \\
\hline Dementia & 512 & 944 \\
\hline Phobia & 272 & 608 \\
\hline Insomnia & 240 & 464 \\
\hline Cluster Headache & 192 & 288 \\
\hline Migraine & 144 & 80 \\
\hline$A D$ & 96 & 128 \\
\hline BDD & 64 & 144 \\
\hline Cerebral Atrophy & 64 & 144 \\
\hline MR & 64 & 16 \\
\hline DDD & 32 & 848 \\
\hline PD & 32 & 176 \\
\hline CAPD & 16 & 32 \\
\hline Cerebral Palsy & 16 & 0 \\
\hline Postpartum Depression & 16 & 0 \\
\hline PTSD & 16 & 0 \\
\hline Hypomania & 0 & 32 \\
\hline Paranoia & 0 & 16 \\
\hline Parkinson's Disease & 0 & 16 \\
\hline ADHD & 0 & 16 \\
\hline
\end{tabular}

NB: ADHD (Attention deficit hyperactivity disorder), AD (Alzheimer's disease), BAD (Bipolar affective disorder), BDD (Body dysmorphic disorder), CAPD (Central auditory processing disorder), DDD (Drug dependence disorder), GAD (Generalized anxiety disorder), MR (Mentally retarded), OCD (Obsessive compulsive disorder), PD (Parkinson's disease), PTSD (Post-traumatic stress disorder) 
Table 3 - Crude prevalence of disorders among the population studied (principal diagnosis)

\begin{tabular}{|c|c|c|c|c|}
\hline \multirow[b]{2}{*}{ Disorders } & \multirow[b]{2}{*}{ Observed Cases (n) } & \multirow{2}{*}{$\begin{array}{c}\text { Crude Prevalence } \\
\text { Rate (\%) }\end{array}$} & \multicolumn{2}{|c|}{ Crude Prevalence (\%) } \\
\hline & & & Female & Male \\
\hline Schizophrenia & 16,464 & 28.6 & 25.2 & 30.4 \\
\hline Depression & 8096 & 14.0 & 20.0 & 10.8 \\
\hline Epilepsy & 6576 & 11.4 & 13.0 & 10.5 \\
\hline GAD & 4864 & 8.4 & 6.5 & 9.5 \\
\hline OCD & 4352 & 7.5 & 6.5 & 8.1 \\
\hline Mood Disorder & 3952 & 6.8 & 5.7 & 7.5 \\
\hline Mania & 2912 & 5.0 & 4.2 & 5.5 \\
\hline BAD & 2496 & 4.3 & 5.3 & 3.8 \\
\hline Psychosis & 2224 & 3.9 & 4.8 & 3.3 \\
\hline Dementia & 1456 & 2.5 & 2.5 & 2.5 \\
\hline DDD & 880 & 1.5 & 0.2 & 2.3 \\
\hline Phobia & 880 & 1.5 & 1.3 & 1.6 \\
\hline Insomnia & 704 & 1.2 & 1.2 & 1.2 \\
\hline Cluster Headache & 480 & 0.8 & 1.0 & 0.8 \\
\hline$A D$ & 224 & 0.4 & 0.5 & 0.3 \\
\hline Migraine & 224 & 0.4 & 0.8 & 0.2 \\
\hline BDD & 208 & 0.4 & 0.3 & 0.4 \\
\hline Cerebral Atrophy & 208 & 0.4 & 0.3 & 0.4 \\
\hline $\mathrm{PD}$ & 208 & 0.4 & 0.2 & 0.5 \\
\hline MR & 80 & 0.1 & 0.3 & 0.0 \\
\hline CAPD & 48 & 0.1 & 0.1 & 0.1 \\
\hline Hypomania & 32 & 0.1 & - & 0.1 \\
\hline Cerebral Palsy & 16 & 0.0 & 0.1 & - \\
\hline Paranoia & 16 & 0.0 & - & 0.0 \\
\hline Parkinsonism & 16 & 0.0 & - & 0.0 \\
\hline $\begin{array}{l}\text { Postpartum } \\
\text { Depression }\end{array}$ & 16 & 0.0 & 0.1 & 0.0 \\
\hline PTSD & 16 & 0.0 & 0.1 & - \\
\hline ADHD & 16 & 0.0 & - & 0.0 \\
\hline
\end{tabular}

NB: ADHD (Attention deficit hyperactivity disorder), AD (Alzheimer's disease), BAD (Bipolar affective disorder), BDD (Body dysmorphic disorder), CAPD (Central auditory processing disorder), DDD (Drug dependence disorder), GAD (Generalized anxiety disorder), MR (Mentally retarded), OCD (Obsessive compulsive disorder), PD (Parkinson's disease), PTSD (Post-traumatic stress disorder). Diagnosis as recorded in patient's notes 
Table 4 - Psychotropic medicines prescribed for neurological and/or psychiatric disorders in order if use by treatment category

\begin{tabular}{|c|c|c|c|c|}
\hline \multirow[t]{2}{*}{ Medicines Prescribed } & \multicolumn{2}{|c|}{ Female } & \multicolumn{2}{|c|}{ Male } \\
\hline & $\mathbf{N}$ & $\%$ & $\mathbf{N}$ & $\%$ \\
\hline Antipsychotics & 23856 & 33.28 & 47648 & 35.08 \\
\hline Clozapine & 8480 & 11.83 & 16640 & 12.25 \\
\hline Risperidone & 6160 & 8.59 & 12160 & 8.95 \\
\hline Olanzapine & 5168 & 7.21 & 10864 & 8 \\
\hline Haloperidol & 2544 & 3.55 & 5504 & 4.05 \\
\hline Quetiapine & 960 & 1.34 & 1536 & 1.13 \\
\hline Fluphenazine & 272 & 0.38 & 592 & 0.44 \\
\hline Levosulpiride & 208 & 0.29 & 112 & 0.08 \\
\hline Zuclopenthixol & 32 & 0.04 & 160 & 0.12 \\
\hline Trifluoperazine & 16 & 0.02 & 32 & 0.02 \\
\hline Ziprasidone & 16 & 0.02 & 32 & 0.02 \\
\hline Flupirtine & 0 & 0 & 16 & 0.01 \\
\hline Antidepressants & 21200 & 29.57 & 39440 & 29.04 \\
\hline Venlafaxine & 6816 & 9.51 & 13520 & 9.96 \\
\hline Mirtazapine & 6352 & 8.86 & 12832 & 9.45 \\
\hline Escitalopram & 2752 & 3.84 & 4704 & 3.46 \\
\hline Fluoxetine & 1936 & 2.7 & 2784 & 2.05 \\
\hline Fluvoxamine & 1568 & 2.19 & 3232 & 2.38 \\
\hline Nortriptyline & 1088 & 1.52 & 1440 & 1.06 \\
\hline Clomipramine & 240 & 0.33 & 528 & 0.39 \\
\hline Citalopram & 192 & 0.27 & 208 & 0.15 \\
\hline Paroxetine & 144 & 0.2 & 112 & 0.08 \\
\hline Tianeptine & 64 & 0.09 & 80 & 0.06 \\
\hline Sertraline & 32 & 0.04 & 0 & 0 \\
\hline Duloxetine & 16 & 0.02 & 0 & 0 \\
\hline Antiepileptics & 10256 & 14.31 & 18000 & 13.25 \\
\hline Sodium Valproate & 6064 & 8.46 & 10896 & 8.02 \\
\hline Carbamazepine & 3296 & 4.60 & 5776 & 4.25 \\
\hline Divalproex Sodium & 368 & 0.51 & 576 & 0.42 \\
\hline Topiramate & 272 & 0.38 & 576 & 0.42 \\
\hline Levetiracetam & 256 & 0.36 & 176 & 0.13 \\
\hline Anxiolytics and hypnotics & 9152 & 12.77 & 16176 & 11.91 \\
\hline Clonazepam & 3136 & 4.38 & 6848 & 5.04 \\
\hline Lorazepam & 2352 & 3.28 & 2976 & 2.19 \\
\hline Alprazolam & 2016 & 2.81 & 2944 & 2.17 \\
\hline Bromazepam & 1488 & 2.08 & 3296 & 2.43 \\
\hline Medazepam & 144 & 0.20 & 96 & 0.07 \\
\hline Oxazepam & 16 & 0.02 & 16 & 0.01 \\
\hline Anti-Parkinson & 4352 & 6.07 & 7728 & 5.69 \\
\hline Procyclidine & 4352 & 6.07 & 7712 & 5.68 \\
\hline
\end{tabular}




\begin{tabular}{|l|c|c|c|c|}
\hline Levodopa/Carbidopa & 0 & 0.00 & 16 & 0.01 \\
\hline Antihistamines & $\mathbf{2 2 8 8}$ & $\mathbf{3 . 1 9}$ & $\mathbf{5 6 9 6}$ & $\mathbf{4 . 1 9}$ \\
\hline Promethazine & 2272 & 3.17 & 5664 & 4.17 \\
\hline Chlorpheniramine & 16 & 0.02 & 32 & 0.02 \\
\hline Miscellaneous & $\mathbf{5 7 6}$ & $\mathbf{0 . 8 0}$ & $\mathbf{1 1 2 0}$ & $\mathbf{0 . 8 2}$ \\
\hline Rivastigmine & 544 & 0.76 & 1040 & 0.77 \\
\hline Memantine & 32 & 0.04 & 48 & 0.04 \\
\hline Trimetazidine & 0 & 0.00 & 16 & 0.01 \\
\hline Clofazimine & 0 & 0.00 & 16 & 0.01 \\
\hline Total number Prescribed & $\mathbf{7 1 6 8 0}$ & $\mathbf{1 0 0 . 0}$ & $\mathbf{1 3 5 8 0 8}$ & $\mathbf{1 0 0 . 0}$ \\
\hline
\end{tabular}

Table 5 - Most frequently prescribed medicines according to sex

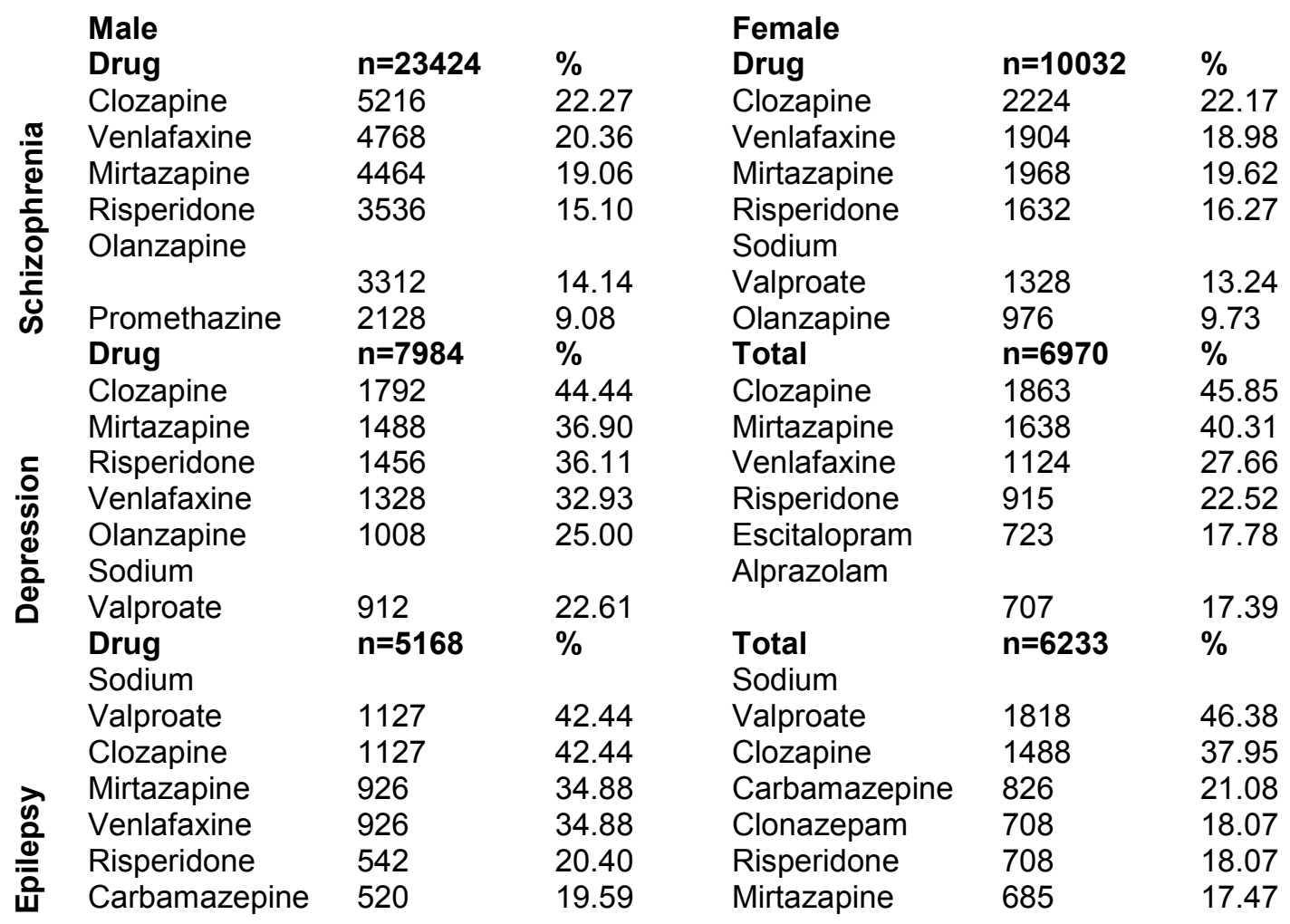


Table 6 - Neurological and psychological disorders among smokers, alcohol and drug misusers

\begin{tabular}{|c|c|c|c|c|c|c|}
\hline \multirow[t]{2}{*}{ Disorder } & \multicolumn{2}{|c|}{$\begin{array}{l}\text { Smokers \% } \\
(\mathrm{N}=15264)\end{array}$} & \multicolumn{2}{|c|}{$\begin{array}{c}\text { Alcohol misuse } \% \\
(\mathrm{~N}=2896)\end{array}$} & \multicolumn{2}{|c|}{$\begin{array}{l}\text { Drug misuse } \% \\
\quad(N=7200)\end{array}$} \\
\hline & $\begin{array}{l}\text { Female } \\
(\mathrm{N}=272)\end{array}$ & $\begin{array}{c}\text { Male } \\
(\mathrm{N}=14992)\end{array}$ & $\begin{array}{l}\text { Female } \\
(N=16)\end{array}$ & $\begin{array}{c}\text { Male } \\
(\mathrm{N}=2880)\end{array}$ & $\begin{array}{l}\text { Female } \\
(\mathrm{N}=48)\end{array}$ & $\begin{array}{c}\text { Male } \\
(\mathrm{N}=7152)\end{array}$ \\
\hline$A D$ & - & 0.32 & - & - & - & 0.67 \\
\hline BAD & 17.65 & 4.16 & - & 1.11 & - & 2.01 \\
\hline BDD & - & 0.43 & - & - & - & 0.22 \\
\hline Cerebral Atrophy & - & 0.43 & - & - & - & 0.67 \\
\hline Cluster Headache & - & 0.85 & - & 0.56 & - & 0.89 \\
\hline Dementia & 5.88 & 2.88 & - & 2.78 & - & 3.36 \\
\hline Depression & 11.76 & 12.91 & 100 & 8.89 & 33.33 & 13.65 \\
\hline DDD & - & 3.09 & - & 3.89 & - & 5.37 \\
\hline Epilepsy & - & 7.90 & - & 6.67 & - & 7.61 \\
\hline GAD & - & 9.39 & - & 9.44 & - & 9.40 \\
\hline Hypomania & - & 0.11 & - & - & - & 0.22 \\
\hline Insomnia & 5.88 & 1.07 & - & 1.11 & - & 1.12 \\
\hline Mania & - & 4.70 & - & 6.67 & - & 4.47 \\
\hline Migraine & 5.88 & - & - & - & - & - \\
\hline Mood Disorder & 5.88 & 8.00 & - & 8.89 & - & 7.38 \\
\hline OCD & 5.88 & 8.00 & - & 7.22 & - & 7.16 \\
\hline Paranoia & - & 0.11 & - & - & - & - \\
\hline PD & - & 0.64 & - & 0.56 & - & 3 \\
\hline Phobia & 5.88 & 1.07 & - & 2.22 & - & 3 \\
\hline Psychosis & 11.76 & 3.31 & - & 4.44 & 33.33 & 14 \\
\hline Schizophrenia & 23.53 & 30.63 & - & 35.56 & 33.33 & 140 \\
\hline NB: AD (Alzheimer's & 20.00 & ar affective & $\mathrm{der}), \mathrm{BD}$ & dy dysmo & c disorder) & DD (Drug \\
\hline
\end{tabular}


Table 7 - Family history

Disorder (N)

Female $(n=1808)$

BAD (208)

CAPD (16)

Cerebral Palsy

(16)

Dementia (16)

Depression

(528)

Epilepsy (336)

GAD (16)

Mania (80)

MR (16)

Migraine (32)

OCD (16)

Psychosis (96)

Schizophrenia (432)

Male $(n=1952)$

BAD (336)

$\operatorname{BDD}(16)$

CAPD (16)

Dementia (16)

Depression

DDD (16)

Epilepsy (608)

GAD (16)

Mania (16)

MR (16)

Migraine (16)

\section{Distribution of disorders}

Children

16 (BAD)

16 (MR)

Sibling

Parents
16 (Cancer)

16 (MR)

16 (Schizophrenia)

16 (BAD)

16 (Depression)

16 (Cerebral Palsy)

16 (BAD)

64( Depression)

32 (Epilepsy)

16 (Schizophrenia)

$16(A D)$

4 (Schizophrenia)

16 (Depression)

80 (MR)

64 (Depression)

16 (ADHD)

32 (Depression)

16 (Epilepsy)

32 (Epilepsy)

128(Epilepsy)

16 (Behavioural

disorder)

16 (BAD)

16 (Depression)

16 (BAD)

16 (BAD)

16 (Depression)

16 (MR)

16 (Epilepsy)

16( MR)

32 (MR)

16 (OCD)

16 (Mania)

16 (Psychosis)

96 (Schizophrenia) 16 (Depression) 32 (MR) 16 (Stroke)

16 (Schizophrenia)

64 (Schizophrenia)

32 (MR)

16 (Drug misusers)

16 (Epilepsy)

5 (BAD)

1 (HCV)

1 (Depression)

16 (Drug misusers)

16 (BAD)

16 (Depression)
112 (BAD)

32 (Schizophrenia)

16 (Epilepsy)

16 (Depression)

16 (CAPD)

16 (Schizophrenia)

32 (Epilepsy)

16 (Behavioural disorder)

16 (Speech disorder)

16 (MR)

48 (Epilepsy) 160 (Epilepsy)

16 (MR) 16 (Sleep walking)
32( Epilepsy)
16 (Depression)

$16(\mathrm{MR})$

16 (BAD)

16 (Drug misusers)

16 (BAD)
16 (BAD)

$16(\mathrm{MR})$

16 (MR) 


$\begin{array}{llll}\begin{array}{l}\text { Mood Disorder } \\ (16)\end{array} & 16 \text { (Drug misusers) } & - & \\ \text { Psychosis (128) } & 16 \text { (MR) } & 16 \text { (Epilepsy) } \\ & 16 \text { (BAD) } & 16 \text { (Psychosis) } \\ \text { Schizophrenia } & 96 \text { (Schizophrenia) } & 16 \text { (Epilepsy \& } & 16 \text { (BAD) } \\ (624) & 16 \text { (BAD) } & 16 \text { (Schizophrenia) } \\ & 16 \text { (Epilepsy) } & & 16 \text { (Psychosis) } \\ & 16 \text { (Depression) } & 16 \text { (Disabled) } \\ & 16 \text { (MR) } & 16 \text { (Epilepsy) } \\ & & 16 \text { (Speech problem) }\end{array}$

NB: ADHD (Attention deficit hyperactivity disorder), AD (Alzheimer's disease), BAD (Bipolar affective disorder), BDD (Body dysmorphic disorder), CAPD (Central auditory processing disorder), DDD (Drug dependence disorder), GAD (Generalized anxiety disorder), MR (Mentally retarded), OCD (Obsessive compulsive disorder), PD (Parkinson's disease), PTSD (Post-traumatic stress disorder). ADHD was often found in multiple siblings 


\section{Appendix}

Table A1 - Disorder ratio broken down by age

\begin{tabular}{|c|c|c|c|c|c|c|}
\hline $\begin{array}{c}\text { Age } \\
\text { bands } \\
\text { (Years) }\end{array}$ & $\begin{array}{c}\text { Female } \\
\text { Disorders }\end{array}$ & $\mathbf{N}$ & \%age & Male Disorders & $\mathbf{N}$ & \%age \\
\hline \multirow[t]{21}{*}{$0-19$} & Epilepsy & 560 & 2.75 & Schizophrenia & 1504 & 4.03 \\
\hline & Schizophrenia & 560 & 2.75 & Epilepsy & 704 & 1.89 \\
\hline & Depression & 240 & 1.18 & GAD & 480 & 1.29 \\
\hline & Psychosis & 160 & 0.79 & Mania & 480 & 1.29 \\
\hline & GAD & 160 & 0.79 & OCD & 480 & 1.29 \\
\hline & Mania & 144 & 0.71 & Depression & 448 & 1.20 \\
\hline & Mood Disorder & 112 & 0.55 & Mood Disorder & 416 & 1.12 \\
\hline & OCD & 112 & 0.55 & Dementia & 208 & 0.56 \\
\hline & BAD & 64 & 0.31 & Psychosis & 176 & 0.47 \\
\hline & Migraine & 48 & 0.24 & Phobia & 128 & 0.34 \\
\hline & MR & 32 & 0.16 & DDD & 96 & 0.26 \\
\hline & CAPD & 16 & 0.08 & BAD & 80 & 0.21 \\
\hline & Cerebral Palsy & 16 & 0.08 & Insomnia & 80 & 0.21 \\
\hline & Cerebral Atrophy & 16 & 0.08 & $A D$ & 32 & 0.09 \\
\hline & AD & 16 & 0.08 & Cluster Headache & 32 & 0.09 \\
\hline & - & - & 0.00 & ADHD & 16 & 0.04 \\
\hline & - & - & 0.00 & CAPD & 16 & 0.04 \\
\hline & - & - & 0.00 & Cerebral Atrophy & 16 & 0.04 \\
\hline & - & - & 0.00 & Migraine & 16 & 0.04 \\
\hline & - & - & 0.00 & PD & 16 & 0.04 \\
\hline & - & - & 0.00 & BDD & 16 & 0.04 \\
\hline \multirow[t]{3}{*}{$20-29$} & Schizophrenia & 1568 & 7.70 & Schizophrenia & 4176 & 11.20 \\
\hline & Depression & 976 & 4.79 & Epilepsy & 1776 & 4.76 \\
\hline & Epilepsy & 976 & 4.79 & Depression & 1632 & 4.38 \\
\hline
\end{tabular}




\begin{tabular}{|c|c|c|c|c|c|c|}
\hline & OCD & 432 & 2.12 & GAD & 1152 & 3.09 \\
\hline & Mood Disorder & 352 & 1.73 & OCD & 1104 & 2.96 \\
\hline & BAD & 304 & 1.49 & Mood Disorder & 1008 & 2.70 \\
\hline & GAD & 304 & 1.49 & Mania & 720 & 1.93 \\
\hline & Psychosis & 240 & 1.18 & BAD & 368 & 0.99 \\
\hline & Mania & 208 & 1.02 & DDD & 368 & 0.99 \\
\hline & Phobia & 112 & 0.55 & Psychosis & 304 & 0.82 \\
\hline & Dementia & 96 & 0.47 & Dementia & 256 & 0.69 \\
\hline & Cluster Headache & 80 & 0.39 & Phobia & 240 & 0.64 \\
\hline & Insomnia & 80 & 0.39 & Insomnia & 192 & 0.51 \\
\hline & $A D$ & 16 & 0.08 & Cluster Headache & 80 & 0.21 \\
\hline & MR & 16 & 0.08 & Cerebral Atrophy & 64 & 0.17 \\
\hline & PD & 16 & 0.08 & PD & 64 & 0.17 \\
\hline & - & - & 0.00 & BDD & 48 & 0.13 \\
\hline & - & - & 0.00 & Migraine & 48 & 0.13 \\
\hline & - & - & 0.00 & $A D$ & 32 & 0.09 \\
\hline & - & - & 0.00 & Hypomania & 32 & 0.09 \\
\hline & - & - & 0.00 & MR & 16 & 0.04 \\
\hline & - & - & 0.00 & Paranoia & 16 & 0.04 \\
\hline $30-39$ & Schizophrenia & 1472 & 7.23 & Schizophrenia & 3152 & 8.45 \\
\hline & Depression & 960 & 4.71 & GAD & 1120 & 3.00 \\
\hline & Epilepsy & 640 & 3.14 & Depression & 896 & 2.40 \\
\hline & GAD & 416 & 2.04 & Mood Disorder & 832 & 2.23 \\
\hline & Mood Disorder & 416 & 2.04 & Epilepsy & 784 & 2.10 \\
\hline & OCD & 368 & 1.81 & OCD & 768 & 2.06 \\
\hline & Psychosis & 304 & 1.49 & Psychosis & 512 & 1.37 \\
\hline & BAD & 288 & 1.41 & Mania & 448 & 1.20 \\
\hline & Mania & 224 & 1.10 & BAD & 384 & 1.03 \\
\hline & Dementia & 128 & 0.63 & Dementia & 272 & 0.73 \\
\hline
\end{tabular}




\begin{tabular}{|c|c|c|c|c|c|c|}
\hline & Insomnia & 112 & 0.55 & DDD & 224 & 0.60 \\
\hline & Phobia & 80 & 0.39 & Insomnia & 128 & 0.34 \\
\hline & BDD & 64 & 0.31 & Phobia & 128 & 0.34 \\
\hline & Cluster Headache & 64 & 0.31 & Cluster Headache & 64 & 0.17 \\
\hline & $\mathrm{AD}$ & 48 & 0.24 & BDD & 48 & 0.13 \\
\hline & Migraine & 48 & 0.24 & PD & 48 & 0.13 \\
\hline & DDD & 32 & 0.16 & $A D$ & 32 & 0.09 \\
\hline & Cerebral Atrophy & 16 & 0.08 & CAPD & 16 & 0.04 \\
\hline & Postpartum Depression & 16 & 0.08 & Cerebral Atrophy & 16 & 0.04 \\
\hline & PTSD & 16 & 0.08 & Migraine & 16 & 0.04 \\
\hline \multirow[t]{17}{*}{$40-49$} & Depression & 832 & 4.08 & Schizophrenia & 1648 & 4.42 \\
\hline & Schizophrenia & 576 & 2.83 & GAD & 544 & 1.46 \\
\hline & BAD & 240 & 1.18 & Depression & 528 & 1.42 \\
\hline & Epilepsy & 208 & 1.02 & OCD & 512 & 1.37 \\
\hline & GAD & 160 & 0.79 & Epilepsy & 480 & 1.29 \\
\hline & Mania & 128 & 0.63 & Mood Disorder & 352 & 0.94 \\
\hline & OCD & 128 & 0.63 & BAD & 336 & 0.90 \\
\hline & Psychosis & 112 & 0.55 & Mania & 272 & 0.73 \\
\hline & Dementia & 96 & 0.47 & Psychosis & 160 & 0.43 \\
\hline & Mood Disorder & 96 & 0.47 & Dementia & 128 & 0.34 \\
\hline & Migraine & 32 & 0.16 & DDD & 112 & 0.30 \\
\hline & Cerebral Atrophy & 16 & 0.08 & Cluster Headache & 96 & 0.26 \\
\hline & Cluster Headache & 16 & 0.08 & Phobia & 96 & 0.26 \\
\hline & Insomnia & 16 & 0.08 & Insomnia & 48 & 0.13 \\
\hline & MR & 16 & 0.08 & Cerebral Atrophy & 32 & 0.09 \\
\hline & Phobia & 16 & 0.08 & PD & 32 & 0.09 \\
\hline & - & - & 0.00 & BDD & 16 & 0.04 \\
\hline \multirow[t]{2}{*}{$50-59$} & Depression & 528 & 2.59 & Schizophrenia & 528 & 1.42 \\
\hline & \begin{tabular}{|l|} 
Schizophrenia \\
\end{tabular} & 448 & 2.20 & Depression & 272 & 0.73 \\
\hline
\end{tabular}




\begin{tabular}{|c|c|c|c|c|c|c|}
\hline & Epilepsy & 176 & 0.86 & BAD & 128 & 0.34 \\
\hline & OCD & 176 & 0.86 & Epilepsy & 128 & 0.34 \\
\hline & GAD & 144 & 0.71 & GAD & 96 & 0.26 \\
\hline & BAD & 128 & 0.63 & Mood Disorder & 80 & 0.21 \\
\hline & Mood Disorder & 80 & 0.39 & Mania & 64 & 0.17 \\
\hline & Dementia & 64 & 0.31 & OCD & 64 & 0.17 \\
\hline & Mania & 64 & 0.31 & Psychosis & 64 & 0.17 \\
\hline & Phobia & 48 & 0.24 & BAD & 32 & 0.09 \\
\hline & Psychosis & 48 & 0.24 & Dementia & 32 & 0.09 \\
\hline & Cerebral Atrophy & 16 & 0.08 & $A D$ & 16 & 0.04 \\
\hline & Cluster Headache & 16 & 0.08 & Cerebral Atrophy & 16 & 0.04 \\
\hline & Insomnia & 16 & 0.08 & Cluster Headache & 16 & 0.04 \\
\hline & Migraine & 16 & 0.08 & DDD & 16 & 0.04 \\
\hline & - & - & 0.00 & Insomnia & 16 & 0.04 \\
\hline & - & - & 0.00 & PD & 16 & 0.04 \\
\hline \multirow[t]{13}{*}{$\begin{array}{c}\text { Above } \\
60\end{array}$} & Depression & 528 & 2.59 & Schizophrenia & 320 & 0.86 \\
\hline & Schizophrenia & 512 & 2.51 & Depression & 256 & 0.69 \\
\hline & GAD & 144 & 0.71 & GAD & 144 & 0.39 \\
\hline & Dementia & 128 & 0.63 & Mood Disorder & 96 & 0.26 \\
\hline & Mood Disorder & 112 & 0.55 & OCD & 96 & 0.26 \\
\hline & OCD & 112 & 0.55 & BAD & 80 & 0.21 \\
\hline & Psychosis & 112 & 0.55 & Mania & 80 & 0.21 \\
\hline & Mania & 96 & 0.47 & Dementia & 48 & 0.13 \\
\hline & Epilepsy & 80 & 0.39 & Epilepsy & 48 & 0.13 \\
\hline & BAD & 64 & 0.31 & DDD & 32 & 0.09 \\
\hline & $A D$ & 16 & 0.08 & Psychosis & 32 & 0.09 \\
\hline & Cluster Headache & 16 & 0.08 & $A D$ & 16 & 0.04 \\
\hline & Insomnia & 16 & 0.08 & BDD & 16 & 0.04 \\
\hline
\end{tabular}




\begin{tabular}{|l|l|c|c|l|c|c|}
\hline & PD & 16 & 0.08 & Parkinsonism & 16 & 0.04 \\
\hline & Phobia & 16 & 0.08 & Phobia & 16 & 0.04 \\
\hline
\end{tabular}

NB: CAPD (Central auditory processing disorder), DDD (Drug dependence disorder), MR (Mentally retarded), PD (Parkinson's disease), ADHD (Attention deficit hyperactivity disorder), AD (Alzheimer's disease), BAD (Bipolar affective disorder), BDD (Body dysmorphic disorder), GAD (Generalized anxiety disorder), OCD (Obsessive compulsive disorder), PTSD (Post-traumatic stress disorder)

Table A2 - Co-morbidities related to neurological and psychological disorders in both male and female populations

\begin{tabular}{|c|c|c|c|c|c|}
\hline Disorder & Co-Morbidities & $\begin{array}{l}\text { No. of } \\
\text { Cases }\end{array}$ & Disorder & Co-Morbidities & $\begin{array}{l}\text { No. of } \\
\text { Cases }\end{array}$ \\
\hline$A D$ & HTN & 16 & $A D$ & DM & 16 \\
\hline \multirow[t]{6}{*}{ BAD } & Depression & 32 & & HTN & 16 \\
\hline & Hep-C & 16 & \multirow[t]{8}{*}{ BAD } & DM, Hep-C & 32 \\
\hline & HTN & 48 & & Hallucinations & 16 \\
\hline & Polio & 16 & & IHD & 16 \\
\hline & Ulcer & 16 & & Hep C & 16 \\
\hline & UTI & 16 & & HTN, DM & 16 \\
\hline BDD & Diabetes & 16 & & Insomnia & 32 \\
\hline $\begin{array}{l}\text { Cerebral } \\
\text { atrophy }\end{array}$ & HTN & 16 & & Paralysis & 16 \\
\hline $\begin{array}{l}\text { Cluster } \\
\text { headache }\end{array}$ & HTN & 32 & & Typhoid & 16 \\
\hline \multirow{4}{*}{$\begin{array}{l}\text { Cerebral palsy } \\
\text { Dementia }\end{array}$} & Speech Delay & 16 & \multirow[t]{2}{*}{ BDD } & DM & 32 \\
\hline & Diabetes & 80 & & HTN & 48 \\
\hline & HTN & 48 & CAPD & Developmental delay & 16 \\
\hline & Schizophrenia, HTN, DM & 16 & \multirow{2}{*}{$\begin{array}{l}\text { Cerebral } \\
\text { atrophy }\end{array}$} & DM & 16 \\
\hline \multirow[t]{17}{*}{ Depression } & Anxiety & 32 & & HTN & 32 \\
\hline & Anxiety \& Insomnia & 16 & \multirow{2}{*}{\begin{tabular}{|l|} 
Cluster \\
headaches
\end{tabular}} & DM & 64 \\
\hline & Asthma & 16 & & HTN & 80 \\
\hline & CA Breast & 16 & \multirow[t]{2}{*}{ Dementia } & DM & 112 \\
\hline & Dengue & 16 & & HTN & 128 \\
\hline & $\mathrm{DM}$ & 208 & \multirow[t]{9}{*}{ Depression } & AIDS & 16 \\
\hline & DM, HTN & 32 & & Anxiety & 16 \\
\hline & HTN & 352 & & $\begin{array}{l}\text { Behaviour Disorder, } \\
\text { Insomnia }\end{array}$ & 16 \\
\hline & Gall bladder Stones & 16 & & HTN & 256 \\
\hline & $\mathrm{IHD}$ & 16 & & DM & 480 \\
\hline & HTN, Insomnia & 16 & & Seizures & 32 \\
\hline & Insomnia & 112 & & Hep-C & 16 \\
\hline & Migraine & 32 & & Insomnia & 48 \\
\hline & Mood Disorder & 16 & & Jaundice & 16 \\
\hline & Partial paralysis & 16 & \multirow[t]{3}{*}{ Epilepsy } & Anemia & 16 \\
\hline & Piles, Nephrolethiasis & 16 & & Anxiety & 32 \\
\hline & Stroke & 16 & & Behavioural Disorder & 32 \\
\hline
\end{tabular}




\begin{tabular}{|c|c|c|c|c|c|}
\hline & Typhoid & 16 & & Blindness & 16 \\
\hline & Ulcer/Severe Headache & 16 & & DM & 384 \\
\hline & Urolithiasis & 16 & & Ear infection & 16 \\
\hline \multirow[t]{11}{*}{ Epilepsy } & DM & 112 & & Seizures & 16 \\
\hline & Seizures & 16 & & Head injury & 32 \\
\hline & HTN & 192 & & Herper zoster & 16 \\
\hline & Mania & 16 & & HTN & 496 \\
\hline & Memory Loss & 16 & & Jaundice & 16 \\
\hline & Meningitis & 16 & & Meningitis & 32 \\
\hline & MR & 16 & & Pneumonia & 16 \\
\hline & Pneumonia & 32 & & Polio & 16 \\
\hline & Psychosis, typhoid & 16 & & Psychosis & 16 \\
\hline & Typhoid & 48 & & $\begin{array}{l}\text { Speech/language } \\
\text { delay disorder }\end{array}$ & 16 \\
\hline & Typhoid, Dengue & 16 & & Typhoid & 128 \\
\hline \multirow[t]{5}{*}{ GAD } & DM & 240 & \multirow[t]{3}{*}{ GAD } & DM & 624 \\
\hline & HTN & 112 & & HTN & 400 \\
\hline & Insomnia & 16 & & Memory loss & 16 \\
\hline & Memory loss & 32 & Hypomania & HTN & 16 \\
\hline & Renal disease, Hep-C & 16 & \multirow[t]{2}{*}{ Insomnia } & DM & 80 \\
\hline \multirow[t]{2}{*}{ Insomnia } & DM & 48 & & HTN & 16 \\
\hline & HTN & 16 & \multirow[t]{4}{*}{ Mania } & DM & 352 \\
\hline \multirow[t]{7}{*}{ Mania } & Anxiety & 16 & & Head injury & 16 \\
\hline & Arthritis & 16 & & HTN & 128 \\
\hline & Depression & 16 & & Typhoid & 16 \\
\hline & DM & 80 & MR & Developmental delay & 16 \\
\hline & HTN & 80 & \multirow[t]{3}{*}{ Mood disorder } & DM & 416 \\
\hline & Memory loss & 32 & & HTN & 336 \\
\hline & Brain Tumour & 16 & & Memory loss & 32 \\
\hline \multirow[t]{3}{*}{$\overline{M R}$} & Developmental delay & 16 & \multirow[t]{5}{*}{ OCD } & Anxiety & 16 \\
\hline & DM & 16 & & Asthma & 16 \\
\hline & Meningitis & 16 & & DM & 512 \\
\hline \multirow[t]{2}{*}{ Migraine } & Anxiety & 16 & & HTN & 480 \\
\hline & Asthma, DM & 16 & & Memory loss & 16 \\
\hline \multirow[t]{2}{*}{ Mood disorder } & DM & 160 & Paranoia & Anxiety & 16 \\
\hline & HTN & 160 & \multirow[t]{2}{*}{ PD } & DM & 32 \\
\hline \multirow[t]{3}{*}{ OCD } & Anxiety & 16 & & HTN & 16 \\
\hline & DM & 288 & \multirow[t]{2}{*}{ Phobia } & DM & 144 \\
\hline & HTN & 224 & & HTN & 48 \\
\hline PD & HTN & 16 & \multirow[t]{4}{*}{ Psychosis } & Anxiety & 16 \\
\hline \multirow[t]{2}{*}{ Phobia } & DM & 32 & & Dengue & 16 \\
\hline & HTN & 32 & & Depression & 16 \\
\hline Psychosis & Angina & 16 & & DM & 80 \\
\hline
\end{tabular}




\begin{tabular}{|l|l|c|c|l|c|}
\hline & Anxiety & 16 & & Epilepsy & 16 \\
\hline & Depression & 64 & & Hep-C & 16 \\
\hline & DM & 64 & & HTN & 96 \\
\hline & HTN & 80 & & TB & 32 \\
\hline & Arthritis & 16 & & Typhoid & 32 \\
\hline & Learning disability & 16 & Schizophrenia & Angina & 16 \\
\hline & Mania & 16 & & Anxiety & 112 \\
\hline & Migraine & 16 & & Arthritis & 16 \\
\hline & MR & 16 & & BAD & 16 \\
\hline & Typhoid & 16 & & Dengue & 16 \\
\hline Schizophrenia & Anorexia & 16 & & DM & 1648 \\
\hline & DM, HTN & 16 & & Head injury & 16 \\
\hline & DM, HTN, Paralysis & 16 & & Hep-C, Depression & 16 \\
\hline & IHD & 32 & & HTN & 1248 \\
\hline & Dengue & 16 & & HTN, DM & 32 \\
\hline & Depression & 64 & & Hydrocephalus & 16 \\
\hline & DM & 544 & & Kidney stone & 16 \\
\hline & Seizures & 16 & & Mania & 16 \\
\hline & Hep-C & 16 & & Memory loss & 32 \\
\hline & HTN & 528 & & MR & 16 \\
\hline & Jaundice & 16 & & Mood disorder & 16 \\
\hline & Memory loss & 32 & & Phobia & 16 \\
\hline & MR & 16 & & Psychosis & 16 \\
\hline & Mood disorder & & Seizures & 32 \\
\hline & Phobia & & Typhoid & 16 \\
\hline
\end{tabular}

NB: AD (Alzheimer's disease), BAD (Bipolar affective disorder), BDD (Body dysmorphic disorder), DM (Diabetes mellitus), GAD (Generalized anxiety disorder), HTN (Hypertension), IHD (Ischemic heart disease), Hep-C (Hepatitis C), MR (Mentally retarded), OCD (Obsessive compulsive disorder), PD (Parkinson's disease), UTI (Urinary tract infection) 